\title{
Ilhas interdisciplinares de racionalidade no ensino de ciências: uma experiência didática no PARFOR na Ilha do Marajó, Pará, Brasil
}

\author{
Interdisciplinary islands of rationality in science teaching: a teaching \\ experience in PARFOR Marajó Island, Pará, Brazil
}

\author{
Jorge Raimundo da Trindade Souza ${ }^{1}$ \\ José Alexandre da Silva Valente ${ }^{2}$ \\ Ana Cristina Pimentel Carneiro de Almeida ${ }^{3}$ \\ Licurgo Peixoto de Brito ${ }^{4}$
}

\section{Resumo}

A pesquisa teve como objetivo analisar o uso da abordagem CTS a partir do desenvolvimento de Ilhas Interdisciplinares de Racionalidade (IIR) com alunos de Licenciatura em Ciências Naturais, na cidade de Breves, Ilha do Marajó (PA). Este curso enfatiza conhecimentos de Química, Física, Biologia e Geociências. A pesquisa foi desenvolvida na disciplina "Prática Docente para o Ensino de Ciências: Educação em Ciências e Tecnologia", culminando com a construção de uma IIR. Para esta análise, além do desenvolvimento da IIR, aplicou-se um questionário para identificação de conhecimentos prévios. A análise foi realizada a partir dos produtos da IIR, das respostas aos questionários e das observações do pesquisador no contexto de uma pesquisa-ação. Conclui-se que o uso da abordagem CTS, a partir de IIR, contribui para evidenciar a relação entre os conhecimentos científicos e o cotidiano.

Palavras-chave: CTS (Ciência, Tecnologia e Sociedade); Ilhas Interdisciplinares de Racionalidade; Ensino de Ciências.

\section{Abstract}

This research had as objective to analyze the use of the STS approach departing from the development of interdisciplinary islands of rationality (IIR) with natural science licentiateship students in the city of Breves, in Marajó Island (PA). This course emphasizes the knowledge from Chemistry, Physics, Biology and Geoscience. The research was developed in the discipline "Teacher Practice for the Teaching of Science: Education in Science and Technology", which culminated with the construction of a IIR. For this analysis, besides the development of IIR, a questionnaire was applied to identify prior knowledge. The analysis was performed from the products of IIR, responses from questionnaires and from observations of the researcher in the context of an action research. It was concluded that the use of the STS approach, departing from IRR, contributes to make evident the relation between scientific knowledge and everyday life.

Keywords: STS (Science, Technology and Society); Interdisciplinary Islands of Rationality; Science Teaching.

\footnotetext{
${ }^{1}$ Universidade Federal do Pará | jrts@ufpa.br

2 Escola de Aplicação da UFPA | alexvalt@ufpa.br

${ }^{3}$ Universidade Federal do Pará | anacrispimentel@gmail.com

${ }^{4}$ Universidade Federal do Pará | licurgo@ufpa.br
} 


\section{Introdução}

A Constituição brasileira de 1988 determina que a educação visa ao pleno desenvolvimento da pessoa, seu preparo para o exercício da cidadania, para a continuidade dos estudos e para a qualificação profissional. Desde então, de acordo com Vaitsman e Vaitsman (2006, p. 3), "O Ensino Médio passou por grandes transformações, que se consolidaram com a publicação, em 1996, da Lei no 9.394 das diretrizes e Bases da Educação Nacional (LDB) ". Ainda segundo os referidos autores (2006, p. 5), "para que o ensino possa apresentar caráter educativo pleno, voltado para a cidadania, a escola deverá oferecer condições e oportunidades para que o aluno organize sua conduta para a saúde, família, trabalho, política, recreação e religião." Sendo assim, ao voltar o olhar para as disciplinas do currículo escolar os autores argumentam que:

A contextualização, no exercício da cidadania, deve permear todas as disciplinas do currículo escolar. A área das Ciências da Natureza deve contribuir para a compreensão de aspectos políticos e éticos referentes ao desenvolvimento científico e, também, favorecer o entendimento do impacto das tecnologias associadas a essas ciências na vida profissional e social e nos processos de produção (VAITSMAN; VAITSMAN, 2006, p. 5).

Observa-se, assim, que desde a promulgação da atual Constituição brasileira, perpassando pela LDB e outros documentos oficiais, diversos autores da área de educação em Ciências demonstram uma preocupação em desenvolver um ensino para que o cidadão possa participar plenamente da sociedade.

As instituições educacionais, até mesmo pelo seu conteúdo variável, podem e devem ajustar-se às reivindicações da sociedade e às características do momento. No entanto, tais instituições de ensino não evoluem com a mesma velocidade do desenvolvimento científico e tecnológico, ocasionando, algumas vezes, situações de exclusão social em uma circunstância que exige o processo de inclusão, uma vez que jovens formados com metodologias e recursos obsoletos são potencialmente excluídos socialmente, ou seja, a conjuntura atual exige um ensino qualificado que permita, ao estudante, maior oportunidade de participação plena na sociedade.

Ricardo (2007), nesse sentido, afirma que a sociedade está mais dependente dos avanços da ciência e da tecnologia. Cada vez mais máquinas sofisticadas que podem trazer diversos benefícios estão à disposição do homem, mas podem criar novas demandas de matérias-primas e produzir novos hábitos e subordinações tecnológicas.

Assim, Carleto e Pinheiro (2010) apontam que o panorama educacional apresenta inúmeros debates em busca de metodologias que busquem a superação das contradições decorrentes de um ensino descontextualizado e conteudista.

É nessa perspectiva que se entende a necessidade de estratégias de ensino contextualizado e que ousem a redução racional do conteúdo em que a aprendizagem de parte deles, que não são estruturantes na Educação Básica, possa ser adiada em favor do fortalecimento da cidadania.

De acordo com Pietrocola (1999), faz-se necessário intensificar as estratégias de construção de conhecimento, a fim de levar o estudante a perceber que o conhecimento científico estabelecido no espaço escolar deve ser utilizado como forma de compreender o mundo que o cerca, sendo, portanto, a realidade um objeto da educação científica e o conhecimento construído pela ciência como esboço dessa realidade. 
Considerando a formação para a cidadania, a contextualização do ensino e a formação escolar que contribuam para incluir na sociedade cidadãos capazes de aplicar conhecimentos científicos básicos em seu cotidiano é que Santos e Schnetzlet questionam:

O que significa ensinar Química para o cidadão? Será que o cidadão precisa de conhecimentos em Química? Será que o ensino de Química que temos ministrado em nossas escolas tem preparado nossos jovens para o exercício consciente da cidadania? Será que ensinar Química para o cidadão é o mesmo que preparar alunos para o vestibular? (SANTOS; SCHNETZLER, 1996, p. 28).

No campo de ciência e tecnologia, novas questões podem ser levantadas. Ao pensar em ciências para todos, Santos (2011, p. 37) pergunta: "Para que todos precisam saber de ciência? Para tomarem decisões sobre CT no cotidiano? Para agirem no seu dia a dia como se fossem cientistas?"

O autor ressalta que

"ao se propor ciência para a cidadania podemos indagar se essa ciência seria uma participação em uma sociedade democrática ou para simplesmente o uso em novas tecnologias? Ou ainda, que ciência queremos para a sociedade? Seria para manutenção do status quo? Que modelo de sociedade queremos?" (SANTOS, 2001, p. 37).

Essas perguntas são necessárias para questionar o modelo de ensino de Ciências que privilegia aspectos científicos em detrimento de questões humanísticas que possam proporcionar o exercício da cidadania.

A sociedade reage a esses questionamentos e, em particular, a comunidade acadêmica busca respondê-los por meio de estudos e reflexões sobre estratégias para tornar o ensino mais contextualizado, humanístico e vinculado ás necessidades da sociedade atual. Nesta perspectiva, dois movimentos surgiram na segunda metade do século passado, nos contextos europeu e americano: O movimento Ciência Tecnologia e Sociedade (CTS) e a Alfabetização Científica e Tecnológica (ACT).

O CTS, que surgiu como um movimento de contestação social, contra os efeitos nocivos da ciência e da tecnologia na sociedade, originou uma tendência de ensino, particularmente de ciências, "o ensino com enfoque CTS", em que se reconhece a ciência como um construto humano, portanto, mutável e sujeito a falhas, ou seja, não dogmático.

Segundo Santos e Mortimer (2001, p. 95), o objetivo central da educação CTS é "O letramento científico e tecnológico para que os alunos possam atuar como cidadãos, tomando decisões e agindo com responsabilidade social", ou seja, a educação CTS parece ter incorporado aspectos da essência da Alfabetização Científica e Tecnológica (ACT) em seu conceito.

A ACT, que tem em Gérard Fourez uma de suas principais referências, surge como concepção de ensino de ciências para a formação de pessoas com visão crítica da ciência e da tecnologia "com as capacidades de saber fazer e de saber ser no mundo técnicocientífico" (Fourez, 1997, p. 15). A respeito das relações entre CTS e ACT, Fourez assim se posiciona:

Em certos meios se fala menos de ACT que do movimento "Ciência, Tecnologia e Sociedade" (CTS). As vezes a realidade designada é a mesma, mas a eleição das palavras aporta matizes. CTS traz à consciência 
um problema que não era considerado como tal a meio século: os vínculos que os polos designam. Enquanto que ao falar de uma ACT (como da promoção de uma cultura científica e tecnológica) não questiona o lugar das ciências e das tecnologias na sociedade, o movimento CTS o faz, ao menos implicitamente (FOUREZ, 1997, p.18).

Fourez considera que, embora o interesse pela ACT esteja polarizado por perspectivas sócioeconômicas, democrática, humanista, a ACT "persegue geralmente três fins: a autonomia do indivíduo (componente pessoal), a comunicação com os demais (componente cultural, social, ético e teórico), e um certo manejo do meio (componente econômico)" (FOUREZ, 1997, p.61).

Fourez (1997) descreve a ACT como uma abordagem epistemológica, pedagógica e mais específica para o ensino das ciências, enquanto que o enfoque CTS tem um caráter amplo, podendo envolver discussões que ultrapassem o meio educacional.

Há, ainda, outras aproximações e distanciamentos entre as abordagens CTS e ACT, que não são objetos deste estudo, no entanto, se faz necessário esclarecer que, apesar de suas convergências, uma abordagem não está incorporada a outra. Diversas informações sobres aproximações e diferenças podem ser encontradas nas obras de Ricardo et al. (2004), Pinheiro e Pinho-Alves (2005), e Sousa (2007).

Alinhada com a nova tendência do ensino de ciências e objetivando inserir esse ensino no cotidiano dos aprendizes, Fourez (1997) sugere a construção de Ilhas Interdisciplinares de Racionalidade, buscando uma alfabetização tecnocientífica. De acordo com Nehring et al. (2002, p. 6) Gérard Fourez define uma Ilha interdisciplinar de racionalidade como "uma invenção de uma modelização adequada para uma situação específica. Para esta construção são utilizados os conhecimentos de diversas disciplinas e os saberes da vida cotidiana".

Segundo Nehring et al. (2002, p. 6),

Fourez estabelece que uma Ilha de Racionalidade designa uma representação teórica apropriada de um contexto e de um projeto, permitindo comunicar e agir sobre o assunto. Refere-se a um contexto e a um projeto particular, para o qual se julga interessante construir uma representação. Ao se construir uma Ilha de racionalidade, surgirão questões específicas ligadas a determinado conhecimento científico que poderão ser respondidas ou não conforme o caso. Estas questões abertas são denominadas de caixas-pretas. $O$ contexto e os objetos do projeto orientam a abertura ou não das caixas-pretas. Uma caixa-preta aberta significa a obtenção de modelos que possam relacionar os fatos conhecidos, gerando explicações. Nesse contexto, uma Ilha de racionalidade ancora-se na construção de modelos, visando à solução de problemas de interesse a partir do cotidiano dos indivíduos.

De acordo com Nehring et al. (2002), Fourez considera que a teorização sugerida na Ilha de Racionalidade quase sempre é interdisciplinar, em decorrência da dificuldade de se encontrar uma solução para um problema real, engessado pelas limitações características da prática disciplinar com uma estrutura cristalizada e viciada.

A construção de uma Iha de racionalidade implica em cruzar saberes provenientes de muitas disciplinas e conhecimentos da vida cotidiana, para estruturar um modelo (ou uma representação, ou uma teorização). A 
eficiência e o valor de uma Ilha de racionalidade estão vinculados a sua capacidade de dar uma representação que contribua para solucionar um problema preciso (NEHRING et al., 2002, p. 7).

Apesar das IIR serem oriundas da concepção de ACT, as convergências entre ACT e CTS, já anunciadas e discutidas por Sousa (2007), permitem encontrar elementos do ensino com enfoque CTS no desenvolvimento de uma IIR. Com base nestas informações, a pesquisa teve como objetivo central analisar o uso da abordagem CTS a partir do desenvolvimento de Ilhas Interdisciplinares de Racionalidade (IIR), com alunos de Licenciatura em Ciências Naturais, na cidade de Breves, Ilha do Marajó (PA). Este objetivo levou à proposição do seguinte questionamento: Como o ensino de Ciências, com enfoque CTS, pode contribuir para que os alunos de Ciências Naturais relacionem o conhecimento científico ao seu cotidiano? Este questionamento delineia um foco na pesquisa que, de outra forma, a deixaria com amplo espectro de características da abordagem CTS a ser investigado. Assim sendo, apresentamos na secção a seguir, as características e a estruturação de uma IIR.

\section{Etapas para a construção de Ilhas Interdisciplinares de Racionalidade (IIR), na perspectiva de uma alfabetização científica e técnica}

Fourez (1997) propõe oito etapas sequenciais a fim de viabilizar a construção de uma IIR, no sentido de promover a Alfabetização Científica e Técnica. Essas etapas também estão descritas em Nehring et al. (2002) e são apresentadas sinteticamente a seguir. Vale ressaltar que não se faz necessário o cumprimento dessas etapas de forma linear, pois "elas são flexíveis e abertas, em alguns casos podendo ser suprimidas e/ou revisitadas, quantas vezes a equipe julgar necessário" (NEHRING et al., 2002, p. 9).

Primeira Etapa - Realizar um clichê da situação: Corresponde à etapa inicial caracterizando-se como uma problematização ou questionamentos iniciais do grupo quase sempre partindo das experiências cotidianas deles. Esses questionamentos poderão refletir suas ideias intuitivas exprimindo suas concepções e dúvidas acerca de um contexto. Convém ressaltar que, nessa etapa, poderão ocorrer pensamentos corretos ou incorretos sobre o contexto estudado muito próprio do início de um estudo. Pode-se, ainda, optar pela palestra de um técnico ou pela desmontagem de um equipamento a ser estudado como o iniciador desse processo. O produto dessa primeira etapa poderá ser a esquematização desses pensamentos iniciais ou a listagem dos questionamentos sobre o contexto a ser estudado.

Segunda Etapa - Elaborar o panorama espontâneo: A intenção aqui é a ampliação do clichê, ainda em processo espontâneo, sem ajuda de especialistas sobre a temática, no qual professores e estudantes levantam outras questões ou revitalizam questões abandonadas no clichê. Nesta etapa, como enfatizam Pinheiro e Pinho-Alves (2005), ocorre: (a) refinamento e/ou melhor delineamento das questões; (b) definição dos participantes; (c) levantamento de normas e restrições de interesses e tensões; (d) listagem dos diversos aspectos da situação que serão abordados no projeto; (e) escolha dos caminhos a seguir; ( $f$ ) 
lista dos especialistas e/ou especialidades relacionados com a temática. Esses aspectos são importantes na orientação das escolhas e dos objetivos metodológicos do projeto.

Terceira Etapa - Consultar os especialistas e as especialidades: Essa etapa ocorre no momento em que determinado assunto envolvido com o projeto não puder ser esclarecido ou dirimido por algum dos membros do grupo. Neste caso, pode se fazer necessária a consulta de um ou mais especialistas, sendo o critério da escolha a situação, o projeto selecionado na etapa inicial e os objetivos escolares, ficando encarregados dessa definição os próprios componentes da equipe do projeto (no caso os professores e alunos). Esta etapa pode ser considerada importante no sentido da definição das possíveis aberturas de caixas-pretas.

Quarta Etapa - Indo à prática: É o momento de "descer ao terreno", como denomina Fourez (1997, p.117). Esta etapa se caracteriza pelo aprofundamento no sentido de buscar informações concretas da situação e do projeto. Segundo Siqueira e Gaertner (2014, p.5), "é a fase mais aproximada do cotidiano, no qual pode haver: entrevistas, saídas de estudo, pesquisas, leituras, desmontar uma ferramenta tecnológica, entre outras práticas. Este é o momento em que saímos do abstrato e trabalhamos com o concreto".

Quinta Etapa - Abertura aprofundada de algumas caixas-pretas (CP), a fim de estabelecer descobertas de princípios disciplinares que fundamentam uma tecnologia: É o momento disciplinar da interdisciplinaridade, pois é possível nesta etapa que se possa trabalhar uma disciplina específica com certa profundidade ou, ainda, ter certos tópicos estudados brevemente. A abertura de CP pode ser realizada com ou sem a ajuda de especialista, sem que se esgote o conhecimento científico e "deve estar em última análise, condicionada ao contexto, ao projeto, aos produtores e destinatários da Ilha de racionalidade", como destaca Nehring et al (2002, p. 12).

Sexta Etapa - Esquematização da situação problematizada: É o momento da construção de uma síntese ainda parcial da Ilha Interdisciplinar de Racionalidade, relatando o que foi estudado e apontando as CP que poderão ser abertas. Siqueira e Gaertner (2014, p.5) destacam que a síntese "pode ser apresentada através de um desenho, mapa conceitual, vídeo, maquete, texto, resumo, enfim, algo que representa o que já foi conquistado".

Sétima Etapa - Abertura de algumas caixas-pretas sem a ajuda de especialistas: Este é um momento de construção autônoma em que os estudantes podem ser estimulados para a abertura de caixas-pretas já listadas anteriormente sem a ajuda de peritos ou especialistas. Esta etapa é importante, pois é possível que os estudantes possam estabelecer modelos e construções, ainda que provisórios e aproximados, que tratam de temáticas do dia-a-dia, o que é interessante no âmbito educacional (NEHRING et al., 2002). Melhor ainda se considerarmos que os recursos tecnológicos (como: internet, revistas, livros, entre outros) atualmente disponíveis podem ajudar nessas aberturas e podem aguçar a curiosidade dos estudantes.

Oitava Etapa - Produto final ou síntese da IIR produzida: Esta é a última etapa da Ilha interdisciplinar de racionalidade produzida. Com isso se faz necessária a sintetização dos variados elementos idealizados durante sua construção. A forma deste produto final pode ser um relatório, uma cartilha, um manual, um CD, um texto síntese etc. Nehring et al. (2002) observam que Fourez considera que o processo de síntese da Ilha se torna importante por inter-relacionar variados elementos. Destacam, ainda, a importância das respostas para as quatro questões: (a) $O$ que é estudado contribui no sentido da 
negociação com o mundo tecnológico analisado?; (b) Produziu certa autonomia no mundo científico-técnico na sociedade em geral? (c) Em que termos os saberes adquiridos podem ajudar a discutir com maior precisão as decisões a serem tomadas? (d) Como isto proporciona uma representação de nosso mundo e história que seja capaz de permitir situar-nos melhor e facilitar uma maior comunicação com os outros?

\section{Aspectos Metodológicos, Análise e Resultados}

Com base em Gil (2010), o trabalho aqui desenvolvido se caracteriza como qualitativo e estudo de campo. A pesquisa qualitativa considera que há uma relação dinâmica entre o mundo real e o indivíduo, fazendo parte dela a interpretação dos fenômenos e a atribuição de significados. Assim, nesta investigação, os pesquisadores participaram para compreender e interpretar os dados coletados.

O envolvimento dos pesquisadores nas ações formativas desenvolvidas durante a investigação sugere que esta seja entendida como uma pesquisa-ação. De fato, a pesquisaação é concebida e realizada em estreita relação e cooperação entre o pesquisador e os participantes representativos da situação em estudo (THIOLLENT, 2007).

Esta pesquisa foi desenvolvida durante a aplicação da disciplina "Prática Docente Para o Ensino de Ciências: Educação em Ciências e Tecnologia", com carga horária de 51h, ministrada no mês de agosto de 2013, para uma turma de Licenciatura em Ciências Naturais PARFOR/UFPA, do campus de Marajó, no município de Breves (PA). A disciplina tem como objetivo proporcionar ao licenciando uma visão geral sobre o enfoque Ciência, Tecnologia e Sociedade (CTS), na educação em ciências, abarcando os aspectos históricos desse movimento educacional, com a perspectiva de utilização de Ilhas Interdisciplinares de Racionalidade (IIR) e abordagens temáticas, como prática pedagógica no ensino de Ciências.

A disciplina compreende cinco momentos distintos: o primeiro, versa sobre a compreensão teórica da perspectiva CTS no ensino de Ciências; o segundo, sobre a proposta curricular CTS; o terceiro, é reservado ao entendimento através da análise de um artigo sobre os aspectos teóricos e metodológicos de uma Ilha Interdisciplinar de Racionalidade; o quarto, versa sobre o uso de temas no ensino de Ciências; e o quinto momento, em forma de oficina, objetivou constituir espaços fecundos de criação de projetos de Ilhas Interdisciplinares de Racionalidade que pudessem ser viabilizados nas escolas onde os alunos do PARFOR atuam como professores. Sobre o quarto momento, que trata dos temas no ensino de Ciências, utilizou-se um texto que aborda o aspecto teórico metodológico dessa modalidade de ensino baseado em Brito e Gomes (2007), seguido da utilização da cartilha temática "Ciências na Amazônia: o viver e o saber do povo das águas" (LIMA, et al., 2006).

Com o objetivo de sondar conhecimentos prévios, foi aplicado um questionário contendo algumas questões que buscavam caracterizar os sujeitos da pesquisa e oito questões sobre ciência, tecnologia e sociedade, com indagações acerca da concepção e utilização do enfoque CTS. Da sistematização das respostas aos questionários, depreendese que, dentre os vinte alunos que participaram da investigação, dezessete eram do sexo feminino e três do sexo masculino, com média de idade de 30 anos.

Todos os sujeitos da pesquisa são alunos de Licenciatura em Ciências Naturais do campus do Marajó, no município de Breves (PA), do Plano Nacional de Formação dos 
Professores da Educação Básica (PARFOR) e são todos professores da Rede Municipal de Ensino sem a formação exigida ("leigos"), com tempo de magistério que varia de dez a quinze anos exercido no Ensino Fundamental.

O PARFOR é destinado aos professores em exercício nas escolas públicas estaduais e municipais, sem formação adequada à LDB. Considerando essa dupla função dos sujeitos, professores na rede municipal de ensino e alunos na universidade, optou-se por fazer referência a eles como alunos, para os fins da pesquisa relatada neste artigo.

Dentre os sujeitos investigados, seis alunos já tinham algum conhecimento sobre a abordagem CTS e quatorze nunca tinham ouvido falar desta tendência educacional. As respostas das perguntas contidas nos questionários não foram objetos de análise direta dos resultados, mas serviram como referências para análise dos conhecimentos prévios sobre o assunto investigado e para determinação de um melhor planejamento metodológico do desenvolvimento da investigação. Assim, foi possível constatar a necessidade de um estudo de alguns conceitos e fundamentos do enfoque CTS.

Anteriormente, antevendo essa possibilidade, um grupo de professores da UFPA, ministrantes da disciplina "Prática Docente Para o Ensino de Ciências: Educação em Ciências e Tecnologia", havia produzido um texto didático acerca da abordagem CTS, para que os alunos pudessem compreender as concepções, fundamentos e estratégias desta abordagem. Esse texto didático foi utilizado para a preparação inicial.

Em seguida, ainda com base nas respostas dos questionários e nos diálogos nas sequências de aulas, definiu-se uma maneira de desenvolver a Ilha Interdisciplinar de Racionalidade, procurando compreender os fatores que motivassem os alunos/professores a realizarem esta atividade. Assim, a Ilha seria desenvolvida em torno das atividades realizadas na Avenida Rio Branco, principal logradouro da cidade, que concentra atividade portuária, comércio, serviços, tráfego intenso por onde flui notadamente a dinâmica urbana do município, inclusive caminhadas como exercício físico e lazer.

Neste trabalho, o desenvolvimento da IIR possui um caráter instrumental, e a abertura das caixas-pretas tem a intencionalidade de exemplificar esta instrumentalização para os alunos do PARFOR que atuam como professores. Nesse sentido, instrumentalizar o professor implica em fundamentar sua prática, municiando-os com estratégias teóricas e metodológicas, levando-os a compreender a importância desses fundamentos no cotidiano da sala de aula.

As etapas propostas por Fourez (1997) já foram abordadas em uma seção específica deste trabalho. No entanto, faz-se necessário elencar novamente o conjunto das etapas nesta seção metodológica para enfatizar o aspecto organizacional de uma IIR: (1) Realizar um "clichê" da situação; (2) Elaborar o panorama espontâneo; (3) Consultar os especialistas e as especialidades, (4) Indo à prática; (5) Abertura aprofundada de algumas caixas-pretas (CP) a fim de estabelecer descobertas de principios disciplinares que fundamentam uma tecnologia; (6) Esquematização da situação problematizada; (7) Abertura de algumas caixaspretas sem a ajuda de especialistas, e (8) Produto final ou síntese da IIR produzida.

Apesar dessas etapas serem apresentadas de forma linear, elas são flexíveis e abertas, podendo, em alguns casos, haver a supressão de algumas ou, ainda, revisitadas pelas equipes proponentes (NEHRING et al, 2002). Segundo esses autores, a equipe é quem determina o intervalo de tempo de cada uma das etapas conforme os objetivos, disponibilidades e necessidades. As etapas servem como um esquema de trabalho, a fim de evitar que ele se torne tão abrangente que não se consiga chegar ao final. 
Com o objetivo de preparar bem os alunos para a atividade anunciada, inicialmente ocorreu uma apresentação teórica sobre IIR realizada pelo professor da disciplina. Posteriormente, os alunos foram divididos em oito equipes para apresentar cada etapa sugerida por Fourez, seguido de debate sobre cada etapa a fim de eliminar dúvidas.

Apesar de se ter definido o tema geral da Ilha, já anunciado, ele não foi transformado logo de início em questão a ser investigada. Optou-se por fazer isso posteriormente, com a ajuda dos alunos. Assim, para orientar a realização do clichê (etapa 1), os alunos foram orientados a ir para as ruas observar "Que conceitos e/ou fenômenos de Química, Física, Biologia, Geociências, Matemática etc., e seus reflexos na sociedade, podem ser observadas ao longo da Avenida Rio Branco, principal logradouro da cidade de Breves? ".

No retorno, os alunos demonstraram dificuldade em indicar as relações intencionadas pelo professor. Este, então, fez um relato de uma IIR desenvolvida em outro contexto a respeito da problemática de um banho saudável. Em seguida, os alunos voltaram à rua. $O$ resultado dessa experiência foi revelador, pois o que parecia pouco provável de ocorrer veio a se confirmar com os depoimentos dos alunos evidenciando adequadamente as relações entre as atividades observadas e fenômenos físicos e químicos. Por exemplo, relataram ocorrência de reação química de combustão nos veículos, fenômenos luminosos e princípios físicos na ótica (venda de óculos na cidade), fenômenos biológicos pela presença de moscas pousadas em alimentos expostos, decomposição de peixes no mercado etc.

Isso possibilitou que o professor os estimulasse e orientasse a aprofundar essas questões. Assim foi feito o Panorama Espontâneo (etapa 2), com a ampliação do Clichê. Ocorre que as oportunidades de investigação surgidas foram tão diversificadas que poderia dar vazão à realização de diversas IIR. Eis as oportunidades levantadas no Panorama Espontâneo: 1) Uma viagem de barco pelo rio Parauau; 2) A água que abastece a cidade de Breves; 3) Uma visita à feira do produtor rural; 4) Poluição sonora no município de Breves; 5) O hábito de jogar lixo nas ruas de Breves; 6) Um passeio pelo hidroviário de Breves; 7) O preparo de um almoço saudável; 8) Realizando compras em um supermercado do município de Breves; 9) Uma caminhada saudável na Avenida Rio Branco, no município de Breves (PA). Cada uma dessas nove ideias poderia constituir-se em uma IIR. Porém, devido à limitação de tempo, a turma optou pelo tema 9 para desenvolver uma Ilha, ficando os demais como sugestões para outras atividades.

Para que sejam claramente definidos o projeto e o contexto "é recomendável que a situação seja expressa por meio de uma questão ou pela descrição da situação, da maneira mais precisa possível." (NEHRING et al, 2002, p. 6). Assim, a IIR desenvolvida passou a ser "Que fenômenos inerentes ao ensino de Ciências Naturais podem ser observados em uma caminhada na Av. Rio Branco, no município de Breves (PA)?"

Como a Ilha iniciou em torno de "Que conceitos e/ou fenômenos de Química, Física, Biologia, Geociências, Matemática etc., e seus reflexos na sociedade, podem ser observadas ao longo da Avenida Rio Branco, principal logradouro da cidade de Breves?", foi realizada uma adaptação no roteiro sugerido por Fourez e a Ilha foi reorientada, apesar de mantida a temática inicial, a partir do panorama espontâneo.

Várias outras etapas das IIR foram desenvolvidas. Para representar seus resultados é apresentado a seguir o texto elaborado pelos alunos como síntese da Ilha "Que fenômenos inerentes ao ensino de Ciências Naturais podem ser observado em uma caminhada na Av. 
Rio Branco, no município de Breves (PA)?" Os indicadores (CP) denotam as caixas-pretas identificadas no processo de discussão.

Caminhar é um hábito saudável (CP) que deveria ser praticado por pessoas que levam vidas sedentárias (CP) tornando-se, por isso, mais propensas a desenvolver doenças cardiorrespiratórias (CP), sem contar que trabalha os demais sistemas do corpo (CP). Propicia ainda higiene mental (CP), bem-estar físico (CP), porém, exige também uma alimentação balanceada (CP), muitas vezes uma boa dieta (CP) e até mesmo acompanhamento de um profissional da área (CP).

A caminhada exige força (CP), resistência física (CP) e preparo físico (CP), porém, é preciso evitar excessos. Deve-se evitar o desgaste físico (CP) e desfrutar de todos os benefícios advindos de uma caminhada.

Ao caminhar pela Avenida Rio Branco, as pessoas caminham pelas calçadas centrais pois, as calçadas laterais são irregulares, o que agride 0 código de postura (CP). Mas ao caminhar pelos canteiros centrais desfruta-se dos benefícios da arborização (CP) no meio ambiente (CP), pois ajuda a bloquear a irradiação solar (CP) prevenindo contra o Câncer de pele (CP). A camada de ozônio (CP) absorve a maior parte da radiação ultravioleta $(C P)$, porém uma pequena porção atinge a superfície da Terra (CP) e acaba provocando o câncer de pele nos seres humanos (CP) e atingindo todas as formas de vida (CP), inclusive as plantas (CP).

Durante a caminhada, pode-se observar o trânsito (CP), um grande fluxo (CP) de carros e motos (liberando gases poluentes), bicicletas, pedestres e outros que transitam sem a menor preocupação em obedecer às leis do trânsito (CP). Como não há sinalização (CP), o risco de acidentes é grande. Os pedestres não podem caminhar pelas calçadas, pois os entulhos (CP) das construções, material de propaganda de lojas e os comércios informais ocupam as calçadas.

Percebe-se, ainda, o grande número de vendedores ambulantes (CP) que algumas vezes vendem alimentos impróprios para o consumo (CP) com pouco cuidado com a higiene (CP). Por isso, é importante o papel da vigilância sanitária (CP). Observam-se, também, pessoas tomando café que está acondicionado em garrafas térmicas (CP) que conservam a temperatura (CP) da bebida (CP).

Em uma caminhada precisamos de água (CP), pois a hidratação $(C P)$ do nosso corpo é fundamental para a nossa saúde (CP). É importante termos conhecimento de onde vem a água que consumimos (CP); se essa água recebe o devido tratamento (CP); qual o órgão responsável pelo abastecimento e distribuição de água no nosso município (CP) e a importância do saneamento básico (CP) para os cidadãos.

Caminhando percebemos a movimentação de pessoas se deslocando para o trabalho (CP) cumprindo o seu papel social (CP); crianças e jovens se dirigindo para as escolas em busca de conhecimento (CP), sabendo que a educação pode ter uma importância grande no seu futuro (CP). 
No decorrer da caminhada, às margens das ruas, percebemos a circulação de pessoas nos hotéis (CP) que movimentam a economia do município (CP), os supermercados (CP) que oferecem produtos diversos $(C P)$ como os alimentos (CP), lojas (CP), óticas (CP), perfumarias (CP) que trazem benefícios para a cidade (CP). As igrejas (CP) também estão presentes na avenida e possuem forte influência na sociedade (CP) fazendo reflexões sobre ética $(C P)$ e conscientização para o bem-estar social (CP).

Não podemos deixar de ressaltar que ao caminharmos precisamos de roupas confortáveis (CP) e tênis apropriados (CP) que são produzidos com matéria-prima (CP) especial para proporcionar o conforto e a comodidade apropriada (CP) para não trazer prejuízo para a nossa saúde $(\mathrm{CP})$.

Na síntese apresentada, foi possível destacar que diversas caixas-pretas (CP) foram estabelecidas e que estavam associadas com a Química (camada de ozônio, gases poluentes, água etc.), com a Física (ótica, força, irradiação solar etc.) e com a Biologia (doenças respiratórias, plantas etc.), além de outras temáticas de caráter interdisciplinar e transversal presentes nessa síntese. Outro aspecto positivo foram as inúmeras relações entre ciências, tecnologia e sociedade, ali estabelecidas, levando-nos a inferir que os alunos parecem ter compreendido a importância dessa tríade na proposta de síntese de Ilha construída.

Após a abertura de algumas caixas-pretas que afloraram, os alunos puderam perceber que, como afirmam Santos e Schnetzler (1996, p. 29), "a função do ensino deve ser a de desenvolver a capacidade de tomada de decisão, o que implica a necessidade de vinculação do conteúdo trabalhado com o contexto social em que o aluno está inserido".

\section{Conclusões}

Hoje, é imperativo que o professor atribua significados aos conteúdos científicos escolares e produza reflexões sobre o papel das ciências e das tecnologias na sociedade. Este estudo revelou que, apesar do pouco conhecimento que os alunos ainda detêm sobre a abordagem CTS, pelo fato de serem alunos de licenciatura em Ciências Naturais, que já que atuam como professores na Educação Básica, compreendem o papel da educação na formação de cidadãos críticos, participativos e reflexivos.

A pesquisa revelou, também, que por meio da aplicação de IIR, os alunos são levados a inferir sobre fenômenos das ciências da natureza, com conhecimentos interdisciplinares, que passam despercebidos no seu cotidiano. Diante deste ponto de vista, a capacidade de construir Ilhas de Racionalidade, dando significado ao conhecimento construído, aparece como essencial à formação de cidadãos com autonomia na sociedade. Assim, pode-se perceber a importância do enfoque CTS na educação, especificamente com a inserção de IIR nos currículos escolares, com a inclusão de temas sociocientíficos, como estratégia para proporcionar a aprendizagem de conceitos e a formação de indivíduos com uma visão crítica da sociedade em que vivem e sua relação com a ciência e com a tecnologia. 
Durante o processo de abertura das caixas-pretas pelos alunos, os aprendizes tiveram a oportunidade de estudar e dirimir dúvidas sobre fenômenos inerentes às Ciências Naturais vivenciados pela sociedade. Assim, as Ilhas Interdisciplinares de Racionalidade proporcionam ao aluno a observação de fenômenos naturais que fazem parte da sua realidade e das suas atividades do dia a dia, que, no entanto, não são percebidos de maneira espontânea no seu cotidiano. Por exemplo, o aluno, ao caminhar de sua residência até o local da escola, perpassa por vários fenômenos que poderiam ser exemplificados no contexto de uma aula de Ciências. Apesar disso, geralmente o professor não consegue visualizar, relacionar e associar esses fenômenos a uma situação de ensino, e isso contribui para que o aluno também não consiga fazer tal associação.

Parece que, como citam vários autores referenciados neste texto, existem dois tipos de ciência: a ciência escolar e a ciência real fora dos muros escolares. Um exemplo pode ser observado no principal logradouro público do município de Breves (PA), na ilha do Marajó (PA): a Avenida Rio Branco, onde vários direitos dos cidadãos brevenses são infringidos, fruto de uma educação escolar que apresenta a ciência aprendida em situação de ensino, dissociada e sem conexão com a ciência que faz parte da vida do aluno, aprendida espontaneamente e de modo empírico. Assim, para o estudante, a ciência escolar proporciona pouco significado na sua vida, pois não relaciona os problemas escolares com os problemas reais vivenciados.

Poluição sonora, poluição visual, falta de acessibilidade para pessoas portadoras de necessidades especiais e até mesmo daquelas pessoas que não possuem tais necessidades, desrespeito às leis de trânsito e desobediência à faixa cidadã, alimentos expostos e acondicionados de maneira incorreta que podem provocar inúmeros tipos de infecções para a população consumidora, despejo de lixo em via pública e o total desrespeito ao código de postura, são apenas alguns exemplos dos direitos transgredidos dos cidadãos do referido município. Exemplificando o desrespeito pela cidadania em Breves, é recorrente observar os pedestres disputarem espaço no meio da rua com os veículos, pelo motivo da ocupação das calçadas por carros ou pelo comércio informal, colocando em risco a vida dos cidadãos.

Os habitantes dos municípios brasileiros, em geral, acomodam-se e não reivindicam seus direitos estabelecidos nas várias leis municipais, estaduais e federais. Esse conformismo, deriva da histórica falta de vínculo entre o ensino escolar e a realidade prática vivenciada pelos alunos, aliada à secular aplicação de uma educação acrítica que contribui para o distanciamento dos verdadeiros objetivos atuais da Educação Básica no Brasil, preconizados na Constituição brasileira de 1988 e na LDB, que objetivam o preparo do estudante para a prática da cidadania, o que pode resultar no exercício do direito de congregar em sociedade e o dever de participar da luta por uma estrutura melhor para si, para seus semelhantes e, enfim, para toda a sociedade brasileira.

Como foi citado neste artigo, para que o ensino possa apresentar caráter educativo voltado para a cidadania, a escola deverá oferecer condições e oportunidades para que o aluno organize sua conduta neste sentido, porém, se para o aluno, atualmente, o panorama é desestimulante, para o professor de Ciências Naturais é uma conjuntura ainda mais preocupante, pois o educador que não consegue compreender a importância da sua missão na sociedade e sua influência nas dimensões humanas, serve simplesmente como mera "correia de transmissão" para a prática dominante. 
Um ensino de Ciências com um enfoque CTS institui, como principal objetivo, estabelecer relações entre os conhecimentos escolares com o desenvolvimento científico e tecnológico e sua aplicação na sociedade, resultando na formação de cidadãos alfabetizados cientificamente. Assim, espera-se que o aluno estimulado para o desenvolvimento de competências, no futuro tenha condições de desempenhar uma função ativa e responsável no meio social em que vive.

Nesse sentido, em situação deliberadamente estruturada, com o objetivo de ensinar algo a alguém, o professor deve rever o seu papel como educador no processo de ensino e aprendizagem, como facilitador da construção de conhecimentos, estimulando os alunos a realizarem reflexões sobre conhecimentos presentes no seu cotidiano, levando-os à tomada de decisões espontâneas para uma sociedade integrada com o desenvolvimento da ciência e da tecnologia.

Neste trabalho, a própria vivência de um dos pesquisadores, como professor da disciplina, transformou-se em dados para a pesquisa pela observação direta sobre a mudança de atitude e postura que os alunos demostraram sobre a importância do ensino de ciências para a formação da cidadania. Observou-se que, na condução das IIR, empregaram-se situações do dia a dia, que não exigiam somente conhecimentos disciplinares. Como as IIR's dependem dos conhecimentos oriundos de várias disciplinas e de saberes da vida real, esta é uma prática que se mostra adequada ao processo de ensino e aprendizagem significativo, pois os problemas cotidianos verdadeiros são essencialmente interdisciplinares e não parece possível que um problema real tenha toda sua complexidade contemplada com a aplicação de uma única disciplina.

Com os resultados obtidos, observa-se que, nesta experiência didática, os alunos aliaram síntese e abrangência, incorporando conceitos e fenômenos observados cotidianamente ao longo do principal logradouro de sua cidade. Conclui-se, assim, que a utilização de Ilhas Interdisciplinares de Racionalidade, em uma perspectiva CTS no ensino de Ciências, é uma atividade acadêmica que pode proporcionar um aprendizado significativo para os estudantes, desde que ocorra a vinculação do conteúdo curricular com o contexto social em que o aluno está inserido.

\section{Referências}

BRITO, L.P.; GOMES, N.F. O ensino de física através de temas no atual cenário do ensino de ciências. In: Encontro Nacional de Pesquisa em Educação em Ciências (ENPEC), 6, 2007, Florianópolis-SC. Anais..., Florianópolis-SC Florianópolis-SC: ABRAPEC, 2007.

CARLETTO, M.R; PINHEIRO, N.A.M. Subsídios para uma prática pedagógica transformadora: contribuições do enfoque CTS. Investigações em Ensino de Ciências - V15(3), p. 507-525, 2010.

FOUREZ, G. Alfabetización Cientifica Y Tecnológica: Acerca de lãs finalidades de la ensenanza de lãs ciências. Buenos Aires, Argentina. Ediciones Colihue, 1997. 249 p.

GIL, A. C. Didática do Ensino Superior. São Paulo: Atlas, 2010.

LIMA, A.C.C.V.; PALHETA, F.C.; DIAS, L.S.; PINHEIRO, S. C. V. Ciências na Amazônia: o viver e o saber do povo das águas. Belém: NPADC / UFPA, 2006. 
NEHRING, C.M.; SILVA, C.C.; TRINDADE, J.A.O.; PIETROCOLA, M.; LEITE, R.C.M.; PINHEIRO, T.F. As ilhas de racionalidade e o saber significativo: o ensino de ciências através de Projetos. ENSAIO - Pesquisa em Educação em Ciências, v.2, n.1, p. 1-18, março, 2002.

PIETROCOLA, M. O. Construção e realidade: o realismo científico de Mário Bunge e o ensino de ciências através de modelos. Investigações em Ensino de Ciências, Porto Alegre, v.4, n.3, p. 213-227, dezembro. 1999.

PINHEIRO, T.F.; PINHO-ALVES, J. Ilhas de racionalidade: experiências interdisciplinares na segunda série do ensino médio. In: Encontro Ibero-Americano de coletivos escolares e redes de professores que fazem investigação na sua escola, 4, 2005, Lajeado (RS). Anais... Lajeado (RS): 2005.

RICARDO, E.C. Educação CTSA: obstáculos e possibilidades para sua implementação no contexto escolar. Ciência \& Ensino, v.1, especial, nov. 2007.

RICARDO, E. C.; CUSTÓDIO, J. F.; REZENDE JUNIOR, M.F.; ALVES FILHO, J.P. A Abordagem CTS e a Alfabetização Científica e Tecnológica: conflitos e aproximações. In: Seminário Ibérico CTS no Ensino das Ciências, 2004, 3 Aveiro. Anais..., 2004.

SANTOS, W.L.P. Significados da educação científica com enfoque CTS. In: SANTOS, W.L.P.; AULER, D. (Org.). CTS e educação científica: desafios, tendências e resultados de pesquisas. Brasília: Editora Universidade de Brasília, 2011. Cap. 1, p. 21-48.

SANTOS, W.L.P.; MORTIMER, E.F. Tomada de decisão para ação social responsável no ensino de ciências. Ciência \& Educação, v.7, n.1, p.95-111, 2001.

SANTOS, W.L.P.; SCHNETZLER, R.P. Função social: O que significa ensino de Química para formar o cidadão? Química Nova na Escola, n. 4, novembro, 1996.

SIQUEIRA, Josiane Bernz; GAERTNER, Rosinéte. Ilhas interdisciplinares de racionalidade: conceito de proporcionalidade na compreensão de informações contidas em rótulos alimentícios. Simpósio Nacional de Ensino e Ciência e Tecnologia (SINECT), 4, 2014, Ponta Grossa (PR). Anais... Ponta Grossa (PR): SINECT, 2014.

SOUSA, R.G. Desafios, potencialidades e compromissos de uma experiência pedagógica para a formação cidadã: Prática CTS construída a partir de uma Ilha Interdisciplinar de Racionalidade sobre reciclagem do lixo urbano. 2007. 196f. Dissertação (Mestrado em Educação em Ciências e Matemáticas) - Núcleo Pedagógico de Apoio ao Desenvolvimento Científico, Universidade Federal do Pará. Belém, 2007.

THIOLLENT, Michel. Metodologia da pesquisa-ação. 15 ed. São Paulo: Cortez, 2007.

VAITSMAN, E.P.; VAITSMAN, D.S. Química \& meio ambiente. Rio de janeiro: Interciência, 2006. 